\title{
Knowledge, Attitude and Practice of Skin Whitening among Female University Students in Northeastern Nigeria
}

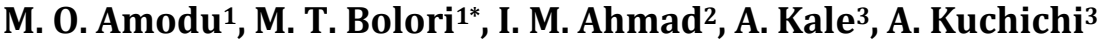 \\ ${ }^{1}$ Department of Community Medicine, University of Maiduguri, Maiduguri, Nigeria \\ ${ }^{2}$ Department of Biochemistry, Kano University of Science and Technology, Kano, Nigeria \\ ${ }^{3}$ Department of Sociology and Anthropology, University of Maiduguri, Maiduguri, Nigeria \\ Email: *mtbolori@gmail.com
}

How to cite this paper: Amodu, M.O., Bolori, M.T., Ahmad, I.M., Kale, A. and Kuchichi, A. (2018) Knowledge, Attitude and Practice of Skin Whitening among Female University Students in Northeastern Nigeria. Open Access Library Journal, 5: e4501. https://doi.org/10.4236/oalib.1104501

Received: March 12, 2018

Accepted: April 15, 2018

Published: April 18, 2018

Copyright $\odot 2018$ by authors and Open Access Library Inc.

This work is licensed under the Creative Commons Attribution International License (CC BY 4.0).

http://creativecommons.org/licenses/by/4.0/

\begin{abstract}
Introduction: Skin whitening is the act of brightening the skin complexion by using substances that are applied on the skin or administered into the body by other means. The use of skin whitening agents has its drawback in terms of causing harmful effects such as skin disorders like depigmentation, rashes, pimples, discolorations, kidney damaged, cancers, neurological and psychiatric disorders depending on how the agents for skin whitening are used. Objective: The paper examines the knowledge, attitude and practice of skin whitening by university female students in north eastern Nigeria, where some dark skinned women in particular tend to bleach their skin. Method: A cross sectional descriptive study. Results: The awareness level of the students about skin whitening agents and their harmful effects was found to be high among the students and little below, half of them are already users of such agents mainly for beautification. Few of them think the use of skin whitening agents can be addictive and lead to social stigma but they don't believe that the use of such agents should be restricted to medical only. Conclusion: Majority of the female students in the Universities in north-eastern Nigeria bleach their skin with dangerous chemical agents meant for other reasons mainly to attract the opposite sex despite having high knowledge of the harmful effects. Government is highly recommended to take the necessary steps to curtail such menace.
\end{abstract}

\section{Subject Areas}

Public Health

\section{Keywords}

Skin Whitening, Knowledge, Attitude, Practice 


\section{Introduction}

Skin whitening used interchangeably with skin bleaching or skin lightening is the act of brightening of the skin complexion using substances, mixtures or physical treatments [1] [2]. Skin whitening is used for aesthetic or cosmetic reasons to increase skin glow, radiance and vibrancy in addition to the lightening [1]. Skin lightening mechanism influences the amount of melanin in the skin to cause effect. Melanin is a pigment produced within the skin to impart its color [3] as well as provide protection against ultraviolet rays of sunlight [2]. Agents used for skin lightening are clinically prescribed for certain medical conditions but are also commercially and widely available without prescription and are obtainable for cosmetic or other reasons from vendors across the streets and across the counter in medicine or cosmetics shops with no control [4]. Adow, in one of his reports for Aljazeera news quoted World Health Organization that $77 \%$ of women in Nigeria apply various agents of skin lightening to their bodies [5]. Nigeria has the highest proportion of women using agents of skin lightening world over. A study conducted in Edo, a state in south-south of Nigeria revealed that $71 \%$ of females and $52 \%$ males actually use skin lightening agents [6]. Practice of skin whitening is also common in other parts of the world such as Middle East and India [7]. The culture of skin whitening is intertwined with personal identity, self-image and racial supremacy [8]. Colonial masters have influenced the colored races especially the ones they have colonized to believe that the white skin is ideal color that matches superiority and power. That perception impacted widely created obsession with use of skin lightening agents among the colored races and shaped the practice of skin whitening by Negroid and other dark skinned to emulate the fair skinned Caucasians in many aspects of life, skin color inclusive. The media also portrays the fair skinned as higher and more prosperous than the black skin through adverts and other productions [9].

The widespread use of the skin lightening agents is not without multifaceted adverse effects [2]. Some associated this habit with prostitution [6]. The default natural texture and color of human skin represent a trademark of beauty and nature's protective gift to man so that he can adapt optimally with potential environmental insults of his natural environment. This is a good example of natural selection strategy at best which needs not to be over emphasized.

Skin whitening substances contain certain of dangerous chemicals such as mercury, steroids, hydroquinone and host of others that have negative health implications [10].

Though some of these chemicals may have non-prescription beneficial side-effects, others are condemned as being source of cumulative toxins and cause health risk and other adverse conditions [3]. All melanin lowering whitening agents carry potential hazards by intervening in the protective activity of melanin. Mercury containing whitening agents have been scientifically proven to cause chronic kidney disease and neurological damage and even psychiatric disorders [3]. 
Skin whitening practice is very rampant in Northeastern Nigeria but its associated disadvantages are not known to majority. There is paucity of study conducted in relation to this menace especially in the face of situation where about $77 \%$ of women in Nigeria use skin lightening agents [5]. Therefore, this work will add to the body of knowledge of the subject matter and highlight aspects that need further study and serve as source of information to aid relevant stakeholders in policy formulation.

This study attempts to expose the level of knowledge of female students on the use of skin whitening products in University of Maiduguri. It tends to bring out the havoc caused by this practice and also the relevant attitude of those practicing the habit. The study will help throw light on how to prevent the dangers associated with the use of skin whitening chemicals. More importantly, the study affords the opportunity to assist and guide government in making policies aimed at curbing the harmful practice of arbitrary and indiscriminate skin whitening.

The objectives of the study include assessment of knowledge, attitude and practice of different pattern and agents for skin whitening in use by students of University of Maiduguri.

Skin whitening used interchangeably with skin bleaching or skin lightening is the practice of brightening of the skin complexion using substances, mixtures or concoctions [1] [2]. The mechanism is mainly by reducing the concentration or production of melanin pigment within the skin [2]. Melanin is the substance responsible for skin color as well as provide protection to the skin against the excesses of the ultraviolet rays that come from the sun [11]. The saying that "black is beautiful" is no more the norm as far as users of skin lightening agents are concerned. Merrick Garland believes that, the fairer a lady is, the more likely she attracts a male compared to darker ones [12].

Agent used for skin whitening

Market for skin lightening agents is booming across the world. In Britain, The Observer uncovered multi-million Pounds market for highly toxic chemicals meant for skin lightening being sold to mostly Asians and Africans [13]. Skin lightening agents commonly used include steroids such as clobetasol, benzene derivatives such as hydroquinone, metals such as mercury. Others include Kojic acid inhibit melanin, Azelaic acid, Glutathione, ascorbic acid which increase levels of glutathione all of which have adverse effects in the body one way or the other.

Toxic skin bleaching agents manufactured in Britain are seen in many countries such as middle east countries, Nigeria, Ghana, Tanzania, Zimbabwe, North Africa and South Africa [13]. These substances are to date very common in all these countries and are freely sold across the counter while they are under serious control or illegal in Britain [13]. According to Jennifer et al, recently, many are considering use of herbal extracts or natural agents of skin bleaching which are less expensive and less toxic or free of toxins [2]. These include honey, cow's milk, turmeric, gram flour, milk of tender coconut, liquorice, mint, asafetida, 
orange \& other citrus fruits, cucumber, almond, papaya, tomato, potato, strawberry, blueberry, blackberry, milk thistle, carrot and others.

Hydroquinone

Hydroquinone is a strong inhibitor of melanin production hence lightening the skin color [2]. Hydroquinone even in small amounts is associated with health risk ranging from skin irritations, itching, discolorations to cancers.

Mercury

Mercury is a common ingredient used in skin whitening soaps and creams serving to lighten the skin color. It gets deposited in tissues like skin, nervous systems, kidneys and lungs to cause dangerous health related conditions such as darkness of nails and skin, Kidney and neurological damage, inflammation of the lungs and stomach discomfort [7].

Steroids

Corticosteroid is very common in the market. Clobetasol is a powerful skin lightening steroid that leads to disorders of skin color, high blood pressure, hormonal imbalance just to mention a few [13].

Knowledge

Majority of the users of skin whitening cosmetics made the discovery themselves aided by either their peers or by patent medicine vendors. Others were introduced to skin whitening by health workers, family members and the media. The usefulness of the black color of the skin in terms of protection from the excesses of ultraviolet rays and the harmful effects of skin lightening is largely reported as not satisfactory in a study conducted in Cameroun [14]. According to Rusmadi et al. about $85 \%$ of the respondents among the undergraduate students knew about the active ingredients in skin bleaching agent they use before buying because of safety reasons [15]. Majority, 95\%, of them knew about the health effect attributed to skin lightening agents agreeing with the findings in South African study in which $89 \%$ respondents having knowledge of adverse effects related to skin lightening agents. Some $61 \%$ were able to mention examples of the dangerous ingredients such as mercury, hydroquinone, tretinoin) in skin lightening agents. Skin lightening agents can lead to cancer (35\%), skin damage (25\%), discoloration (6\%) and infections (4\%).

It was demonstrated that most $(83.6 \%)$ of high school girls in north-west of Nigeria knew that use of skin whitening agents is a risk factor for cancer [16].

A Research conducted in Malaysia shows that majority of both undergraduates and postgraduates students are aware of the health effects related to skin whitening products [15]. This is consistent with a study in South Africa where 89 per cent of the respondents agree that skin whitening can produce adverse effect to their skin.

Attitude

About $64 \%$ of Nigerians feel that skin lightening has become highly predominant in the country [17]. Various reasons were given for using whitening products. Some of these were to look more attractive to the opposite sex (32\%), just 
to feel beautiful (35\%) and to remove feeling of inferiority (4\%). A study showed that most common perception of respondents in Lahore was that majority (82\%) of men considers women with lighter skin appearance to be more beautiful and have greater chance of getting married (70.5 per cent). There is perception that women with lighter skin tone implies that they belong to a higher social class (19.7 per cent) [17]. A group of researchers reported that some respondents (25\%) have the perception of lighter skin color implies that the user belongs to higher social class [17].

There is opinion among ladies that fairness of the skin goes with added advantage of being more confident, powerful, sexy and more attractive to men. Whiteness of the skin is considered as superior to the blackness. The physical features such as skin color, hair color and straightness are believed to be part of beauty and attractiveness. There is attitude of some that fairness of skin is associated with intelligence, purity, power and success [7]. In South Asian region there was perception that skin color of the white race that were the colonizers was superior to the darker skin color [15]. Perhaps this could be the reason why celebrities use skin lightening creams and make their hair look straight like that of the whites.

Various reasons were given for using whitening products. Some of these were to look more attractive to the opposite sex (32\%), just to feel beautiful (35\%) and to remove feeling of inferiority (4\%). It has been shown that most common perception of respondents in Lahore is that majority (82\%) of men consider women with lighter skin to be more beautiful and that lighter skin tone increases woman's chance of getting married (70.5 per cent) and light skin tone is more beautiful (59 per cent) [15]. From the least perception they had is that lighter skin tone implies that women belong to a higher social class (19.7 per cent). It has also been concluded in one study that $25 \%$ the respondents have the perception that persons with lighter skin color belong to higher social class [15]. No significant difference in the respondents' knowledge about skin whitening agents and perception between undergraduates and post graduates [15]. Contrary to the popular belief that skin lightening is considered as cosmetic by some, dermatologists actually prescribe skin bleaching agents as treatment to for skin diseases.

Skin lightening agents reduce pigment called melanin in the skin as mechanism of action to lighten the skin to make it more uniform. Skin lightening agents have dangerous side effects ranging from skin irritations, itching, discolorations such as ochronosisto cancer [13]. Understanding the dangers involved in irrational use of skin lightening agents can reduce the dangers that are encountered in the use of these agents.

Practice

The practice of skin whitening has always been reported among adults in the past but the trend has change now with involvement of large number of female adolescent group [17]. This practice is on the rise due to socialization. It is true that skin whitening practice cuts across all ages, races, beliefs and ideologies 
[15]. In Nigeria, the practice was found to be common among all age groups and gender [17]. However, studies indicate a much higher prevalence in young, unmarried and educated women [17]. Various additives are added to the products to enhance whitening effect. Some of the additives (concoction) are lemon juice, potash, tooth paste, liquid milk, pulverized Naphthalene (camphor) balls. Sometimes detergents are added to the concoction [18]. Hydroquinone based cosmetics are the most frequently used and mercury based ones are the least used [19].

It is evident that facial whitening is more frequently practiced than any other patterns. However, the reason for choosing which type or pattern of skin whitening depends largely on the individual and the purpose of doing it. At the initiation of the practice, a total body surface application is often used for maximum effect. This is then maintained with daily application of the products. Multiple products containing different agents may be used concurrently or sequentially [18]. Skin lightening agents are used very commonly in Korea, Japan and China [20]. Adow, in one of one of his report for Aljazeera news quoted World Health Organization that $77 \%$ of women in Nigeria apply various agents of skin lightening to their bodies [6]. Nigeria has the highest proportion of women using agents of skin lightening world over. A study conducted in Edo, a state in South-south of Nigeria revealed that $71 \%$ of females and 52 per cent males actually use skin lightening agents [6]. In Pakistan the prevalence of use of skin lighteners was reported as 59\% by Askari et al. [9]. In Malaysia 60\% of respondents who were mostly (85\%) less than 25 years of age among female university students were users of skin brightening agents [15]. A girl was brought back home (Nigeria) very sick due to overuse of skin lightening agents from European country [15].

Prostitution is another significant factor which could be responsible for skin whitening practice [9] [21]. Skin whitening was found to be practiced by prostitutes as a method of attracting the opposite sex [22]. This happens to be very common among commercial sex workers and many of those who camouflage as fashion designers because of the stigma associated with prostitution. Some who are already fair in complexion by nature are found to use skin lightening agents to avoid tanning of the skin by sun [18].

The practice of skin whitening has always been reported among adults in the past but the trend has change now with involvement of large number of female adolescent group [17]. This practice is on the rise due to socialization. It is true that skin whitening practice cuts across all ages, races, beliefs and ideologies [15]. In Nigeria, the practice is common place at all ages; both among men and women. However, studies indicate a much higher prevalence in young, unmarried and educated women [17].

Methodology, the study was conducted from 13/3/2017 to 10/4/2017 in the University of Maiduguri situated in Borno, a state in North-Eastern part of Nigeria with latitude $11.5 \mathrm{~N}$ and longitude $13.5 \mathrm{E}$. English is the official language in the area of study but Kanuri and Hausa are widely spoken as languages. The 
University in which the study was conducted has 12 faculties with total of about 25,000 students mainly from within Nigeria and few from other parts of Africa and beyond.

The study was a cross sectional descriptive one. Study population was all the female students of the University. Sample size of 384 was calculated using the

$$
\text { formula } n=Z \cdot p / q d \times d \quad[23] \text {. }
$$

where $n=$ sample size, $Z=$ standard normal deviate, which is usually $1.96, p=$ prevalence rate $=0.5$. By convenience method 4 departments were arbitrarily selected from five faculties where female students were higher in proportion. A self-administered questionnaire which consist of open and close ended questions were administered to the consenting respondents with the aim of capturing information on biodata, knowledge, attitudes and practice of skin whitening.

Data analysis was conducted by using the Statistical Software for Social Sciences, SPSS version 24.0.0. Frequency Tables 1-6 and graphs were used to display the data.

Table 1. Socio-demographic data of respondents.

\begin{tabular}{|c|c|c|}
\hline Socio-demographic characteristics & Frequency & Percentage \\
\hline \multicolumn{3}{|l|}{ Age $(n=395)$} \\
\hline $15-19$ & 67 & $17.0 \%$ \\
\hline $20-24$ & 205 & $51.9 \%$ \\
\hline $25-29$ & 89 & $22.5 \%$ \\
\hline $30-34$ & 26 & $6.5 \%$ \\
\hline $35-39$ & 8 & $2.0 \%$ \\
\hline \multicolumn{3}{|l|}{ Marital status $(\mathrm{n}=395)$} \\
\hline Married & 80 & $20.3 \%$ \\
\hline Divorced & 3 & $0.8 \%$ \\
\hline Separated & 5 & $1.3 \%$ \\
\hline Widowed & 6 & $1.5 \%$ \\
\hline Single & 301 & $76.2 \%$ \\
\hline \multicolumn{3}{|l|}{ Ethnicity $(\mathrm{n}=389)$} \\
\hline Kanuri & 86 & $22.1 \%$ \\
\hline Shuwa & 36 & $9.3 \%$ \\
\hline Hausa & 60 & $15.4 \%$ \\
\hline Igbo & 37 & $9.5 \%$ \\
\hline Yoruba & 25 & $6.4 \%$ \\
\hline Others & 145 & $37.3 \%$ \\
\hline \multicolumn{3}{|l|}{ Religion $(n=395)$} \\
\hline Islam & 269 & $68.1 \%$ \\
\hline Christianity & 125 & $31.6 \%$ \\
\hline No response & 1 & $0.3 \%$ \\
\hline \multicolumn{3}{|l|}{ Children $(\mathrm{n}=80)$} \\
\hline$<3$ & 60 & $74.1 \%$ \\
\hline $3-5$ & 18 & $22.2 \%$ \\
\hline $6-8$ & 2 & $3.7 \%$ \\
\hline
\end{tabular}


Table 2. Respondents' knowledge of skin whitening.

\begin{tabular}{|c|c|c|}
\hline & Frequency & Percentage \\
\hline \multicolumn{3}{|c|}{ Heard of skin whitening agents $(\mathrm{n}=395)$} \\
\hline Yes & 378 & $95.7 \%$ \\
\hline No & 17 & $4.3 \%$ \\
\hline \multicolumn{3}{|l|}{ Source $(\mathrm{n}=378)$} \\
\hline Friends & 195 & $51.6 \%$ \\
\hline Family member & 68 & $18.0 \%$ \\
\hline Media & 92 & $24.3 \%$ \\
\hline Chemist & 13 & $3.4 \%$ \\
\hline Others & 8 & $2.1 \%$ \\
\hline No response & 2 & $0.5 \%$ \\
\hline \multicolumn{3}{|c|}{ Use of skin whitening agents $(n=378)$} \\
\hline Yes & 182 & $48.1 \%$ \\
\hline No & 189 & $50.0 \%$ \\
\hline No response & 7 & $1.9 \%$ \\
\hline \multicolumn{3}{|c|}{ Know active ingredients $(\mathrm{n}=378)$} \\
\hline Yes & 166 & $43.9 \%$ \\
\hline No & 205 & $54.2 \%$ \\
\hline No response & 7 & $1.9 \%$ \\
\hline \multicolumn{3}{|c|}{ Source of knowledge of ingredients $(\mathrm{n}=378)$} \\
\hline Labels or leaflets & 80 & $21.2 \%$ \\
\hline Friends & 65 & $17.2 \%$ \\
\hline Advertisement & 20 & $5.3 \%$ \\
\hline Others & 1 & $0.3 \%$ \\
\hline No response & 212 & $56.1 \%$ \\
\hline \multicolumn{3}{|c|}{ Who bleach more? $(\mathrm{n}=378)$} \\
\hline Married women & 45 & $11.9 \%$ \\
\hline Unmarried women & 332 & $87.8 \%$ \\
\hline No response & 1 & $0.3 \%$ \\
\hline
\end{tabular}

Table 3. Respondents knowledge of side effects and recognition of users of skin whitening agents.

\begin{tabular}{ccc}
\hline & Frequency (\%) & Percentage \\
\hline Side effect $(\mathrm{n}=182)$ & 162 & \\
Yes & 15 & $89.1 \%$ \\
No & 5 & $8.2 \%$ \\
No response & & $2.7 \%$ \\
Yes & 292 & \\
No & 79 & $77.2 \%$ \\
No response & 7 & $20.9 \%$ \\
Recognition of users ( $=378)$ & & $1.9 \%$ \\
How to recognize users (n 378$)$ & 19 & \\
Beautiful \& fair looking & 131 & $5.0 \%$ \\
Depigmentation & 38 & $34.7 \%$ \\
Sun burn, pimples \& rashes & 50 & $10.1 \%$ \\
Very fair skin & 36 & $13.2 \%$ \\
Dark spot \& knuckle & 5 & $9.5 \%$ \\
Smooth \& shinning & 13 & $1.3 \%$ \\
Body odor & 86 & $3.4 \%$ \\
No response & & $22.8 \%$ \\
\hline
\end{tabular}


Table 4. Attitude of respondents on skin whitening.

\begin{tabular}{|c|c|c|c|}
\hline Attitude & Agree & Indifferent & Disagree \\
\hline $\begin{array}{l}\text { Do you use skin whitening agents because of the } \\
\text { environment that you are located? }\end{array}$ & $62(33.3 \%)$ & $34(21.9 \%)$ & $86(44.8 \%)$ \\
\hline Do you find it more of a beauty factor? & $102(56.0 \%)$ & $10(5.5 \%)$ & $70(38.5 \%)$ \\
\hline $\begin{array}{l}\text { Do you think if you had a lighter complexion you } \\
\text { will be treated better? }\end{array}$ & $62(34.1 \%)$ & $29(15.9 \%)$ & $91(50.0 \%)$ \\
\hline $\begin{array}{l}\text { Do you think the use of skin whitening products } \\
\text { should be used only for medical purposes? }\end{array}$ & $41(22.5 \%)$ & $62(34.1 \%)$ & $79(43.4 \%)$ \\
\hline $\begin{array}{l}\text { Do you think the use of skin whitening products } \\
\text { would make you have more suitors? }\end{array}$ & $57(31.3 \%)$ & $21(11.5 \%)$ & $104(57.1 \%)$ \\
\hline $\begin{array}{l}\text { Do you think the use of skin whitening products } \\
\text { would make other stigmatize you? }\end{array}$ & $45(24.7 \%)$ & $32(17.6 \%)$ & $105(57.7 \%)$ \\
\hline Can skin whitening be addictive? & $92(50.5 \%)$ & $30(16.5 \%)$ & $60(33.0 \%)$ \\
\hline
\end{tabular}

Table 5. Practices of skin whitening respondents.

\begin{tabular}{|c|c|c|}
\hline & Frequency & Percentage \\
\hline \multicolumn{3}{|c|}{ Duration $(\mathrm{n}=182)$} \\
\hline$<1$ year & 91 & $50.0 \%$ \\
\hline 1 - 4 years & 75 & $41.2 \%$ \\
\hline $5-9$ years & 14 & $7.7 \%$ \\
\hline$>10$ years & 2 & $1.1 \%$ \\
\hline \multicolumn{3}{|l|}{ Time $(\mathrm{n}=182)$} \\
\hline Daily & 81 & $44.5 \%$ \\
\hline Twice daily & 71 & $39.0 \%$ \\
\hline Weekly & 14 & $7.7 \%$ \\
\hline Others & 16 & $8.8 \%$ \\
\hline \multicolumn{3}{|c|}{ Combination $(\mathrm{n}=182)$} \\
\hline Yes & 87 & $47.8 \%$ \\
\hline No & 95 & $52.2 \%$ \\
\hline \multicolumn{3}{|c|}{ Herbs $(\mathrm{n}=182)$} \\
\hline Yes & 32 & $17.6 \%$ \\
\hline No & 150 & $82.4 \%$ \\
\hline \multicolumn{3}{|l|}{ Kind $(n=182)$} \\
\hline Creams & 108 & $59.3 \%$ \\
\hline Soaps & 45 & $24.7 \%$ \\
\hline Syrups & 20 & $10.9 \%$ \\
\hline Injectable & 3 & $1.6 \%$ \\
\hline Pills & 4 & $2.2 \%$ \\
\hline Others & 2 & $1.1 \%$ \\
\hline \multicolumn{3}{|c|}{ Recommend $(\mathrm{n}=182)$} \\
\hline Yes & 71 & $39.0 \%$ \\
\hline No & 91 & $50.0 \%$ \\
\hline No response & 20 & $11.0 \%$ \\
\hline
\end{tabular}


Table 6. Choice of body parts and brand names for skin whitening by respondents.

\begin{tabular}{ccc}
\hline & Frequency & Percentage \\
\hline Choice of skin whitening agent $(\mathrm{n}=182)$ & & \\
Brand name & 39 & $21.4 \%$ \\
Friends & 104 & $57.1 \%$ \\
Advertisement & 19 & $10.4 \%$ \\
Sample & 20 & $11.0 \%$ \\
All body parts $(\mathrm{n}=182)$ & & \\
Yes & 132 & $72.5 \%$ \\
No & 50 & $27.5 \%$ \\
Fther preferred part $(\mathrm{n}=50)$ & & \\
Face & 39 & $78.0 \%$ \\
Upper part & 10 & $20.0 \%$ \\
Lower part & 1 & $2.0 \%$ \\
\hline
\end{tabular}

Ethical considerations

Approval to conduct the research was obtained from the ethical committee the University of Maiduguri Teaching Hospital. Each responded had consented to participate in the study by signing the informed consent from accompanying the questionnaire.

Limitations

Limitations of Study of the study were restriction to undergraduate female students of in one representative University of Maiduguri only out of the many tertiary institutions in the northeastern Nigeria.

\section{Results and Discussions}

Most of the respondent belong the age bracket of 20 to 24 years which is the typical age of undergraduate students as in Table 1. Average age was 23.2 years. About $20.3 \%$ of the respondents were married and a quarter of them have at least 3 children. Table 2 shows majority (95.7\%) of the respondents know about skin whitening agents or at least heard mainly from friends (51.6\%) and media (24.3\%). About $43.9 \%$ of them knew the active substances in skin whitening creams through reading the leaflets $(21.2 \%)$ or were told by friends $(17.2 \%)$. As far as most $(87.8 \%)$ of respondents are concerned single ladies use skin whitening agents more than the married ones. The study showed that out of the female students who bleach their skin $11.9 \%$ tend to be unmarried while the remaining $(87.9 \%)$ tend to be unmarried.

Slightly below half $(48.1 \%)$ of the respondents were active users of skin whitening agents as the time of the study. That was less than the $77 \%$ that was reported for the whole of Nigeria [5] and 71\% for only Edo state1qq in south-south of Nigeria. Up to $89.1 \%$ of the respondents asserted knowing the side effects of skin whitening agents as found in South Africa [5]. Table 3 showed $89.1 \%$ of the respondents knew that skin whitening agents have side effects matching the findings in South Africa [14]. Many (77.2\%) could identify a user of skin whi- 
tening agent because of certain typical features. Some of the striking features seen on user of skin whitening agents include depigmentation (34.7\%), features of sun burn, pimples and rashes (10.1\%), dark spots and knuckles (9.5\%) and body odor (3.4\%).

By way of attitude, only few (33\%) of the respondents agree that the habit of skin whitening has anything to do with environmental conditions while $45 \%$ disagree. However, significant proportion (56.0\%) feel see skin whitening as a beautification factor compared to $39 \%$ who see it the other way round. Up to $34 \%$ of users of skin whitening agents think of getting better treatment from others with fairer skin unlike the greater proportion who do not think so. Many (43.4\%) of the respondents asserted that the use of skin whitening should not be restricted to medical use only while the remaining do not think the same way. Skin whitening can lead to getting a suitor faster according to $31 \%$ as oppose to believe of the remaining. About $57.7 \%$ believe that there is no stigmatization attached to use of skinning whitening agents. However, $24.7 \%$ of respondents agree that stigmatization is an issue in use of skin whitening agents. Up to $50.5 \%$ believe that addiction to use of skin whitening agent can occur while $33.0 \%$ were opposed to such believe and others remain undecided.

Table 4 shows Sixty-two (33.3\%) of the respondents were of the opinion that environment has influence on the use of skin whitening agents. Even though, about $56.0 \%$ as opposed to $38.5 \%$ of the respondents think that fair complexion of the skin is a factor for beauty, they don't think that it attracts more suitors $(57.1 \%)$ or attract better treatment from others $(50.0 \%)$. This agrees with findings in other studies in which lighter skin is associated superior qualities of beauty, influence and power [7] [14]. Few (34.1\%) of the respondents think fairness of the skin may attract better treatment from others. Perhaps the quest for power and better treatment from may part of the reason why celebrities use skin lightening creams and hair straightening to look like the whites [14]. Some others feel that skin fairness can be associated with some stigmatization $(24.7 \%)$. According to some (50.5\%) of the respondents' skin whitening can be addictive.

Table 5 showed that half $(50.0 \%)$ of those that use the skin whitening agents did so for a period of less than one year followed by about $41.2 \%$ of the respondents who used it for a period of between one to four years. The finding of this study showed that majority of the users of the skin whitening agents do so at least once $(44.5 \%)$ or twice $39.0 \%$ daily. Some use combination of different agents $(47.8 \%)$. This is not surprising as there is report in which some users of skin bleaching agents that go beyond mere combinations to add substances like lemon juice, potash, tooth paste, milk, pulverized naphthalene balls and detergents [17]. About 17.6\%admitted of using herbs. Creams are the skin whitening agents that are most frequently (59.3\%) used. Others agents used are in form of soap (24.7\%), syrups (10.9\%), injectable (1.6\%), pills $(2.2 \%)$ and others $(1.1 \%)$.

Some of the respondents admitted recommending their type of skin whitening practices to others $(39.0 \%)$ as oppose to $(50.0 \%)$ that did not recommend.

Out of the 182 respondents who were using skin whitening agents 127 (69.8\%) 
were single, $48(26.4 \%)$ were married while the remaining 7 (3.8\%) were widowed, divorced or separated from their spouses. The 127 single respondents that were using bleaching agent form $42.1 \%$ of all (301) respondents in the study that were single. This is just slightly less than the finding that $77 \%$ of the women in Nigeria are in the habit of using skin bleaching agents [5]. It also agrees with the study that showed most of the women who bleach their skin belong to the category of young, single and educated women [17].

Majority of the respondents, $(57.1 \%)$ choose the product by friend's recommendation, while others go by reading the brand name on labels $(21.4 \%)$ or through advertisements (10.4\%) and samples (11.0\%) as in Table 6. Most of the respondents $(72.5 \%)$ include the whole of the body for skin lightening. Four fifths of the remaining $27.5 \%$ include only the face.

\section{Recommendations}

The youths in the Universities should be empowered through the school curricular to be contented and have self-satisfaction and confidence with their natural endowments in terms of their skin color.

The harmful effects due to use of skin whitening agents should also be mentioned when such substances are being advertised even for medical reasons just like in the case of tobacco marketing.

Media should stop promoting skin whitening as a means of promoting cosmetic products for commercial reasons by making the white skin color to sound or look superior to the others.

The sales of skin whitening agents in places like Nigeria should be banned in Nigeria in the same way as it is banned in England and other parts of the United Kingdom.

\section{References}

[1] Essence (2016) This Is the Real Difference between Skin Brightening and Skin Lightening [Internet].

https://www.essence.com/beauty/skin/difference-between-skin-lightening-and-skin -brightening

[2] Jennifer, C., Stephie, C.M., Abhishri, S.B. and Shalini, B.U. (2012) A Review on Skin Whitening Property of Plant Extracts. International Journal of Pharma and Bio Sciences, 3, 332-347.

[3] WebMD (2017) Skin Lightening Treatments [Internet]. https://www.webmd.com/beauty/skin-lightening-products\#1-3

[4] Gillbro, J. and Olsson, M.J. (2011) The Melanogenesis and Mechanisms of Skin-Lightening Agents: Existing and New Approaches. International Journal of Cosmetic Science, 33, 210-221. https://doi.org/10.1111/j.1468-2494.2010.00616.x

[5] Adow, M. (2017) Nigeria's Dangerous Skin Whitening Obsession. Aljazeera [Internet]. http://www.aljazeera.com/indepth/features/2013/04/20134514845907984.html

[6] Burger, P., Landreau, A., Azoulay, S., Michel, T. and Fernandez, X. (2016) Skin Whitening Cosmetics: Feedback and Challenges in the Development of Natural Skin Lighteners. Cosmetics, 3, 36. https://doi.org/10.3390/cosmetics3040036 
[7] Ofili, A.N., Eze, E.U. and Onunu, A.N. (2006) Prevalence of Use of Skin Lightening Agents amongst University of Benin Undergraduates in Benin City. Nigerian Medical Practitioner, 49, 24-27.

https://www.ajol.info/index.php/nmp/article/view/28789 https://doi.org/10.4314/nmp.v49i1.28789

[8] Thacker, P. (2015) Skin-Lightening or Bleaching Is a Common Practice Not Only in Africa But in Parts of Asia and the Middle East. Another African Nation Bans Popular Skin-Whitening Creams. Skin Deep [Internet].

http://nytlive.nytimes.com/womenintheworld/2015/05/12/another-african-nation-b ans-popular-skin-whitening-creams/

[9] Toure, A. (2012) Bleached and Black. http://www.kathryntoure.net/docs/skin_bleaching-by-AyaToure.pdf

[10] Blay, Y.A. () Skin Bleaching and Global White Supremacy: By Way of Introduction. The Journal of Pan African Studies, 4.

[11] Askari, S.H., Sajid, A., Faran, Z. and Sarwar, S.Z. (2017) Skin-Lightening Practice among Women Living in Lahore: Prevalence, Determinants, and User's Awareness. Skin-Lightening Practice among Women Living in Lahore [Internet]. https://cgr.umt.edu.pk/icobm2013/papers/Papers/IC3-Dec-2012-066.pdf

[12] Williams, J. (2017) What Is Melanin? Definition, Production \& Function. Lesson Transcript. Human Biology Study Guide. Study.com [Internet]. https://study.com/academy/lesson/what-is-melanin-definition-production-function .html\#transcriptHeader

[13] Olajide, O. (2017) Skin Lightening: 7 Reasons Why Girls Bleach. Hermaze [Internet]. https://hermaze.com/skin-lightening-7-reasons-why-girls-bleach/

[14] The Observer (2005) Toxic Creams for Sale as Thousands Seek Whiter Skin [Internet]. https://www.theguardian.com/uk/2005/oct/16/health.healthandwellbeing

[15] Kouotou, E.A., Nansseu, J.R.N., Adegbidi, H., Mebara, T.C.J.Z. and Ndam, E.C.N. (2017) Skin Whitening among Cameroonian Female University Students: Knowledge, Attitudes, Practices and Motivations. BMC Women's Health [Internet]. https://bmcwomenshealth.biomedcentral.com/articles/10.1186/s12905-017-0385-Z

[16] Rusmadi, S.Z., Syed Ismail, S.N. and Praveena, S.M. (2015) Preliminary Study on the Skin Lightening Practice and Health Symptoms among Female Students in Malaysia. Journal of Environmental and Public Health, 2015, Article ID: 591790. https://doi.org/10.1155/2015/591790

[17] Sule, S.T., Shehu, S.M. and Ukwenya, J.E. (2014) Risk Factors for Common Cancers in Nigeria: Knowledge, Attitudes and Practice among Secondary School Students in Kaduna, Nigeria. International Journal of Medicine and Medical Sciences, 6, 34-41. https://doi.org/10.5897/IJMMS2013.0970

[18] NOIPoll (2014) Predominance of Skin Bleaching Linked to Search for Beauty and Attractiveness. http://www.noi-polls.com

[19] Olumide, Y.M., Akinkugbe, A.O., Altraide, D., Mohammed, T., Ahamefule, N., Ayanlowo, S., Onyekonwu, C. and Essen, N. (2008) Complication of Chronic Use of Skin Lightening Cosmetics. International Journal of Dermatology, 47, 344-353. https://doi.org/10.1111/j.1365-4632.2008.02719.x

[20] Adebajo, S.B. (2002) An Epidemiological Survey of the Use of Cosmetic Skin Lightening Cosmetics among Traders in Lagos, Nigeria. WA Journal of Medicine, 21, 51-55.

[21] Beautiful White Skin. Effective, Safe Skin Lightening for More Attractive You [Internet]. http://beautifulwhiteskin.com/skin-lightening/celebrities-rihanna-beyonce/ 
[22] Olumide, Y.M. (2016) The Vanishing Black African Woman. A Compendium of Global Skin Lightening Practice. Vol. 1. https://books.google.com.ng/

[23] Araoye, M.O. (2004) Research Methodology with Statistics for Health for and Social Sciences. Nathadex Publishers, Kwara (Nigeria). 